\title{
Development and Validation of UV Spectrophotometric Method for Simultaneous Equation of Aspirin and Omeprazole in Tablet Dosage Form
}

\author{
Sandip S Chaudhari* and Swapnil D Phalak \\ TVES's HLMC College of Pharmacy, Maharashtra, India
}

\begin{abstract}
YOSPRALA is newly designed tablet which effective in cardiovascular as well as gastrointestinal protection due to its immediate release of Omeprazole $(40 \mathrm{mg})$ and delayed release of Aspirin $(81 \mathrm{mg})$ or $(325 \mathrm{mg})$ dose strength. Yosprala was approved by USFDA in Sept 2016 for cardiovascular and cerebrovascular diseases.

Aspirin is an antiplatelet agent \& Omeprazole is proton pump inhibitor therefore it is made to develop a new analytical method for Simultaneous estimation of Aspirin and Omeprazole using Mehtanol as a solvent on the basis of solubility. The maximum Absorption ( $\lambda$ max) of Aspirin and Omeprazole was found at 276 and 301 respectively. Linearity range for aspirin was given at $10-50 \mu \mathrm{g} / \mathrm{ml}$ with \%RSD value 0.997 and Omeprazole was $2-10 \mu \mathrm{g} / \mathrm{ml}$ with \%RSD value 0.997 . The method was validated for precision and \% RSD was found less than 2.0 for both aspirin and omeprazole. The proposed method was statistically validated for standard deviation, relative standard deviation, coefficient of variance and the results were within the range. Hence the above method was simple, cheap, cost effective, economical, and robust.
\end{abstract}

Keywords: Yosprala; Aspirin; Omeprazole; UV spectroscopy; $\lambda$ max

\section{INTRODUCTION}

Aspirin is an antipletelet agent while omeprazole is proton pump inhibitor used in combination for treatment of stroke and other cardiovascular disease. On extensive literature survey it was found that very few methods are reported for Simultaneous estimation of Aspirin and Omeprazole in combined dosage form by any analytical technique. These methods were developed on single Aspirin only or combination with other drugs by using UV spectroscopy in tablet dosage form, hence i was decided to develop a new method which having accurate, precise, economical, rapid and cost effective (Figure 1) [1]

Aspirin [2-(acetyloxy) benzoic acid], acts as an inhibitor of cyclooxygenase which results in the inhibition of the biosynthesis of prostaglandins. It also inhibits platelet aggregation and is used in the prevention of arterial and venous thrombosis (Figure 2) [2].

Omeprazole is a proton pump inhibitor used in the treatment of dyspepsia, peptic ulcer disease (PUD), Gastro esophageal reflux disease (GORD/GERD), Laryngopharyngeal reflux (LPR) and Zollinger-Ellison syndrome.

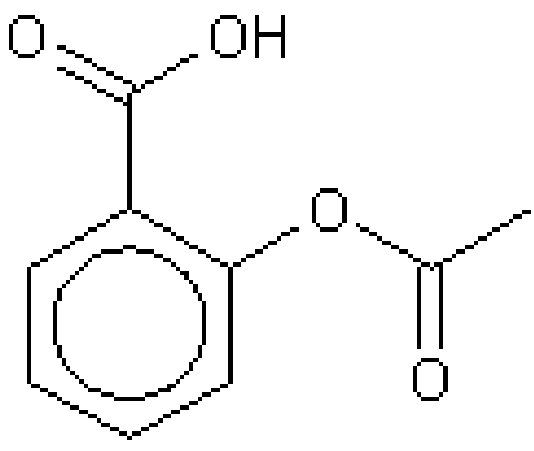

Figure 1: Aspirin.

Omeprazole is entirely metabolised by the hepatic cytochrome P-450 system (CYP), mainly in the liver. Identified metabolites in plasma are the sulfone, the sulfide and hydroxyomeprazole [3].

Simultaneous equation method is used where a sample contains two absorbing drugs (X and Y) each of this absorbance $\lambda_{\max }$ of each other, it may be possible to determine both the drugs by the technique of simultaneous equation method.

${ }^{*}$ Correspondence to: Sandip S Chaudhari, TVES's HLMC College of Pharmacy, Faizpur, Maharashtra, India, Tel: 9922246400; E-mail: Sandipc246@ gmail.com

Received: January 03, 2020; Accepted: February 20, 2020; Published: February 27, 2020

Citation: Chaudhari SS, Phalak SD (2019) Development and Validation of UV Spectrophotometric Method for Simultaneous Equation of Aspirin and Omeprazole in Tablet Dosage Form. Pharm Anal Acta 11:618. doi: 10.35248/2153-2435.20.11.618

Copyright: (C) 2020 Chaudhari SS, et al. This is an open-access article distributed under the terms of the Creative Commons Attribution License, which permits unrestricted use, distribution, and reproduction in any medium, provided the original author and source are credited. 
<smiles>COc1ccc2[nH]c(S(=O)Cc3ncc(C)c(OC)c3C)nc2c1</smiles>

Figure 2: Omeprazole.

\section{MATERIAL AND METHODS}

\section{Chemicals and reagents}

The bulk drug of pure Aspirin powder was obtained from Alta laboratories, Mumbai and Omeprazole from Blue Cross Laboratories, Nasik. Yosprala tablets were procured from local market. All chemicals and reagents of analytical grade were purchase from Merck Chemical, Mumbai, INDIA

\section{Instrument}

A double beam Shimadzu UV-visible spectrophotometer model 1800 with UV probe software was used for absorption measurements.

\section{Solubility}

As per solubility studies it was found that both the drug sample are freely soluble in methanol.

\section{Determination of $\lambda$ max of individual component}

An appropriate aliquot portion of ASP $(0.5 \mathrm{~mL})$ and $\mathrm{OMZ}(0.1$ $\mathrm{mL}$ ) were transferred to two separate $10 \mathrm{~mL}$ volumetric flasks, the volume was made up to the mark using $80 \% \mathrm{v} / \mathrm{v}$ methanol to obtain ASP $(50 \mu \mathrm{g} / \mathrm{mL})$ and OMZ $(10 \mu \mathrm{g} / \mathrm{mL})$. Drug solutions were scanned separately between $200 \mathrm{~nm}$ to $400 \mathrm{~nm}$ [4].

The overlain spectrum of both drugs having concentrations $130 \mu \mathrm{g} /$ $\mathrm{mL}$ ASP and $16 \mu \mathrm{g} / \mathrm{mL} \mathrm{OMZ}$ was recorded and two wavelengths $276.0 \mathrm{~nm}(\lambda \max$ of ASP) and $301.0 \mathrm{~nm}(\lambda \max$ of OMZ) were selected for further study [5].

\section{Preparation of standard stock solutions of ASP and OMZ}

A) Aspirin standard stock solution [A]: An accurately weighed quantity of ASP (10 mg) was taken in $10 \mathrm{~mL}$ volumetric flask and dissolved in methanol $(8 \mathrm{~mL})$ with the help of ultrasonication for about $10 \mathrm{~min}$. Then the volume was made up to the mark using methanol to get Aspirin standard stock solution (1 mg / mL) [6].

B) Omeprazole standard stock solution [O]: An accurately weighed quantity of OMZ (10 mg) was taken in $10 \mathrm{~mL}$ volumetric flask and dissolved in methanol $(8 \mathrm{~mL})$ with the help of ultrasonication for about $10 \mathrm{~min}$. Then the volume was made up to the mark using methanol to get Omeprazole standard stock solution $(1 \mathrm{mg} / \mathrm{mL})$ (Tables 1, 2 and Figures 3-6) [7-9].

\section{RESULT AND DISCUSSION}

Results of Standard Laboratory Mixture (API) and YOSPRALA Tablet by UV-Spectroscopic methods (Table 3).
Table 1: Linearity Study of ASP at $276 \mathrm{~nm}$.

\begin{tabular}{cccc}
\hline Sr. No. Concentration of ASP & $\begin{array}{c}\text { Absorbance } \\
\text { in }[\mu \mathrm{g} / \mathrm{mL}]\end{array}$ & \% R.S.D. \\
\hline 1 & 10 & $0.073 \pm 0.0008$ & 1.142 \\
\hline 2 & 20 & $0.112 \pm 0.0007$ & 0.631 \\
\hline 3 & 30 & $0.165 \pm 0.0018$ & 1.133 \\
\hline 4 & 40 & $0.212 \pm 0.0011$ & 0.536 \\
\hline 5 & 50 & $0.265 \pm 0.0008$ & 0.315 \\
\hline
\end{tabular}

Table 2: Linearity Study of OMZ at $301 \mathrm{~nm}$.

\begin{tabular}{cccc}
\hline Sr. No. & $\begin{array}{c}\text { Concentration of } \\
\text { OMZ in }[\mu \mathrm{g} / \mathrm{mL}]\end{array}$ & $\begin{array}{c}\text { Absorbance } \\
\text { Mean } \pm \text { S.D. }[\mathrm{n}=5]\end{array}$ & \% R.S.D. \\
\hline 1 & 2 & $0.0588 \pm 0.0018$ & 1.117 \\
\hline 2 & 4 & $0.1052 \pm 0.0019$ & 1.828 \\
\hline 3 & 6 & $0.1622 \pm 0.0014$ & 0.914 \\
\hline 4 & 8 & $0.225 \pm 0.0012$ & 0.544 \\
\hline 5 & 10 & $0.2744 \pm 0.0018$ & 0.662 \\
\hline
\end{tabular}

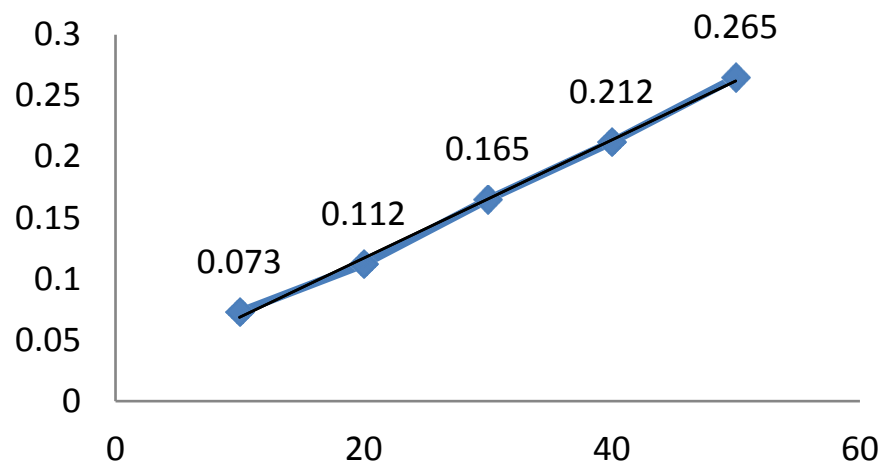

Figure 3: Calibration Curve of Aspirin at $276 \mathrm{~nm}$.

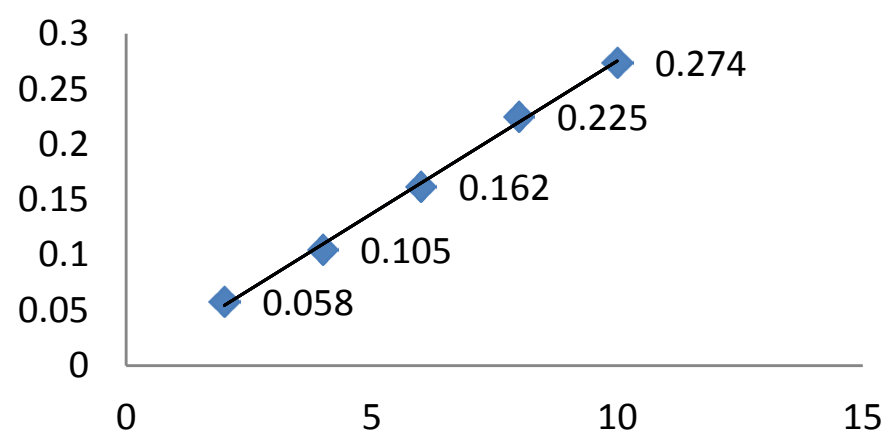

Figure 4: Calibration Curve of Omeprazole.

\section{Validation of proposed method}

The Proposed method was validated as per the ICH guidelines.

\section{Accuracy [recovery study]}

Accuracy of proposed method was ascertained on the basis of recovery study performed by standard addition method (Tables 4).

\section{Precision}

According to ICH guidelines acceptance criteria for precision the \%RSD should NMT 2\% (Table 5). 


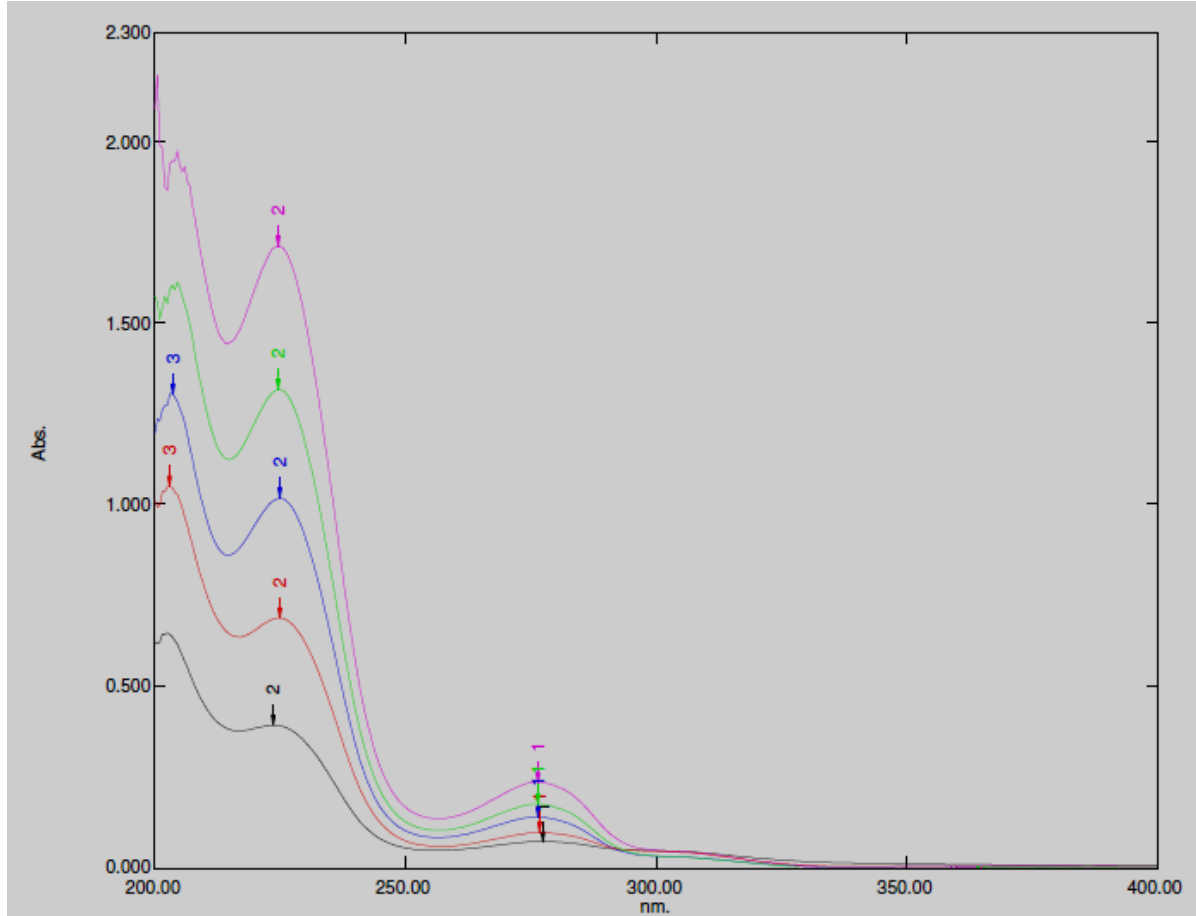

Figure 5: Overlay Spectra of ASP at $276 \mathrm{~nm}$.

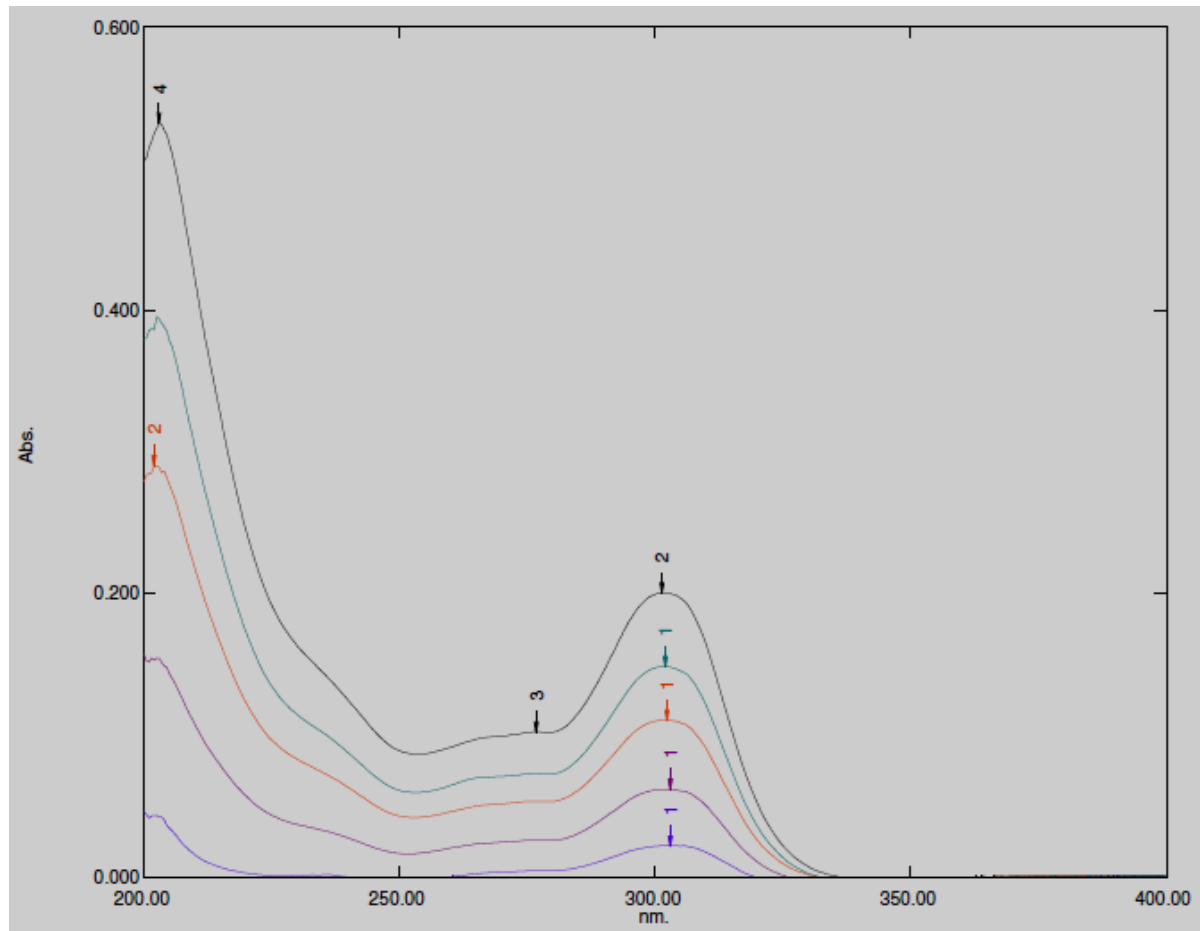

Figure 6: Overlay Spectra of OMZ at $301 \mathrm{~nm}$.

Table 3: Summary of Results for UV-spectroscopic methods.

\begin{tabular}{|c|c|c|c|c|}
\hline \multirow[t]{2}{*}{ Sr. No } & \multirow[t]{2}{*}{ Sample } & \multirow[t]{2}{*}{ Statistical data } & \multicolumn{2}{|c|}{ \%Label Claim } \\
\hline & & & ASP & $\mathrm{OMZ}$ \\
\hline \multirow[t]{3}{*}{1.} & \multirow[t]{3}{*}{ Standard Laboratory Mixture (API) } & Mean & 99.85 & 99.80 \\
\hline & & S.D. & 0.0764 & 0.0697 \\
\hline & & \% R.S.D & 0.0766 & 0.0699 \\
\hline \multirow[t]{3}{*}{2.} & \multirow[t]{3}{*}{ YOSPRALA Tablet } & Mean & 99.87 & 99.85 \\
\hline & & S.D. & 0.0702 & 0.0465 \\
\hline & & \% R.S.D & 0.0703 & 0.0466 \\
\hline
\end{tabular}


Table 4: Recovery Study.

\begin{tabular}{|c|c|c|c|c|c|c|c|c|}
\hline \multirow[t]{2}{*}{$\begin{array}{l}\text { Sr. } \\
\text { No. }\end{array}$} & \multirow{2}{*}{$\begin{array}{c}\text { Quantity } \\
\text { Tablet } \\
\text { Powder } \\
\text { Taken }\end{array}$} & \multirow[t]{2}{*}{$\begin{array}{c}\text { Percentage } \\
\%\end{array}$} & \multicolumn{2}{|c|}{$\begin{array}{l}\text { Amount of Pure } \\
\text { Drug Added (mg) }\end{array}$} & \multicolumn{2}{|c|}{$\begin{array}{c}\text { Total Amount of Drug Recovered }(\mathrm{mg}) \\
\pm \text { S.D. }(\mathrm{n}=3)\end{array}$} & \multicolumn{2}{|c|}{$\begin{array}{l}\% \text { of Drug Recovered } \\
(\mathbf{n}=3)\end{array}$} \\
\hline & & & ASP & OMZ & ASP & $\mathrm{OMZ}$ & ASP & $\mathrm{OMZ}$ \\
\hline 1. & 478 & 80 & 260 & 32 & $583.3 \pm 1.08$ & $71.64 \pm 0.06$ & 99.70 & 99.50 \\
\hline 2. & 478 & 100 & 325 & 40 & $649.6 \pm 1.17$ & $79.91 \pm 0.05$ & 99.95 & 99.88 \\
\hline \multirow[t]{4}{*}{3.} & 478 & 120 & 390 & 48 & $714.7 \pm 1.43$ & $87.95 \pm 0.02$ & 99.90 & 99.94 \\
\hline & & & & & & Mean & 99.85 & 99.77 \\
\hline & & & & & & SD & 0.1322 & 0.2386 \\
\hline & & & & & & $\%$ RSD & 0.1324 & 0.2388 \\
\hline
\end{tabular}

Table 5: Precision study.

\begin{tabular}{|c|c|c|c|c|c|}
\hline & \multirow[t]{2}{*}{$\begin{array}{l}\text { Conc. } \\
{[\mu \mathrm{g} / \mathrm{mL}]}\end{array}$} & \multicolumn{2}{|c|}{$\begin{array}{c}\text { Intra-day } \\
\text { Amount Found }\end{array}$} & \multicolumn{2}{|c|}{$\begin{array}{c}\text { Inter-day } \\
\text { Amount Found }\end{array}$} \\
\hline & & $\begin{array}{c}\text { Mean } \pm \text { S.D } \\
{[n=5]}\end{array}$ & $\begin{array}{c}\% \\
\text { R.S.D. }\end{array}$ & $\begin{array}{c}\text { Mean } \pm \text { S.D. } \\
\quad[n=5]\end{array}$ & $\begin{array}{c}\% \\
\text { R.S.D. }\end{array}$ \\
\hline \multirow[t]{3}{*}{ ASP } & 10 & 9.940 .064 & 0.6462 & $9.92 \pm 0.1013$ & 1.0213 \\
\hline & 20 & 19.890 .1814 & 0.9121 & $19.86 \pm 0.2309$ & 1.1622 \\
\hline & 30 & 29.790 .272 & 0.9156 & $29.75 \pm 0.3614$ & 1.2147 \\
\hline \multirow[t]{3}{*}{ OMZ } & 2 & $1.97 \pm 0.081$ & 0.5452 & $1.95 \pm 0.0151$ & 0.7753 \\
\hline & 4 & 3.920 .0336 & 0.856 & $3.91 \pm 0.0420$ & 1.0737 \\
\hline & 6 & $\begin{array}{lll}5.87 & 0.0342\end{array}$ & 0.5819 & $5.83 \pm 0.0707$ & 1.2128 \\
\hline
\end{tabular}

Table 6: Ruggedness study.

ASP $325 \mu \mathrm{g} / \mathrm{mL}$

$\begin{array}{ccc}\text { Parameters } & \begin{array}{c}\text { Amount Found in } \mu \mathrm{g} / \mathrm{mL} \text { Mean } \\ \pm \text { S.D. }(\mathbf{n}=3)\end{array} & \% \text { RSD } \\ \text { Analyst I } & 324.46 \pm 0.3614 & 0.1113 \\ \text { Analyst II } & 324.95 \pm 0.3968 & 0.1221 \\ \text { Day-I } & 324.29 \pm 0.6340 & 0.1955 \\ \text { Day-II } & 325.06 \pm 0.6562 & 0.2019 \\ \text { Instrument I } & 324.21 \pm 0.7379 & 0.2276 \\ \text { Instrument II } & 324.89 \pm 0.8580 & 0.2641\end{array}$

$\mathrm{OMZ} 40 \mu \mathrm{g} / \mathrm{mL}$

\begin{tabular}{|c|c|}
\hline $\begin{array}{l}\text { Amount Found in } \mu \mathrm{g} / \mathrm{mL} \text { Mean } \pm \\
\text { S.D. }(\mathrm{n}=3)\end{array}$ & $\% \mathrm{RSD}$ \\
\hline $39.78 \pm 0.1484$ & 0.3730 \\
\hline $39.82 \pm 0.1569$ & 0.3940 \\
\hline $39.77 \pm 0.1861$ & 0.4678 \\
\hline $39.80 \pm 0.1908$ & 0.4795 \\
\hline $39.73 \pm 0.2753$ & 0.6930 \\
\hline $39.70 \pm 0.2662$ & 0.6707 \\
\hline
\end{tabular}

Table 7: System suitability parameters.

\begin{tabular}{cccc}
\hline Sr.no & Parameters & Aspirin & Omeprazole \\
\hline 1 & $\lambda \max$ & $276 \mathrm{~nm}$ & $301 \mathrm{~nm}$ \\
\hline 2 & Regression co-efficient $(\mathrm{r} 2)$ & 0.997 & 0.997 \\
\hline 3 & LOD $(\mu \mathrm{g} / \mathrm{ml})$ & 0.2528 & 0.2307 \\
\hline 4 & LOQ $(\mu \mathrm{g} / \mathrm{ml})$ & 1.766 & 1.954 \\
\hline 5 & Linearity range & $10-50 \mu \mathrm{g} / \mathrm{ml}$ & $2-10 \mu \mathrm{g} / \mathrm{ml}$ \\
\hline
\end{tabular}

\section{Ruggedness}

LOD: Limit of detection of Aspirin and Omeprazole were found to be $0.2528 \mu \mathrm{g} / \mathrm{mL}$ and $0.2307 \mu \mathrm{g} / \mathrm{mL}$ respectively (Table 6).

LOQ: Limit of Quantitation of Aspirin and Omeprazole were found to be $1.766 \mu \mathrm{g} / \mathrm{mL}$ and $1.954 \mu \mathrm{g} / \mathrm{mL}$ respectively.

\section{System suitability parameters}

The following parameters are system suitability parameters for the analytical method developed according to ICH guidelines (Table 7).

\section{CONCLUSION}

It was through to develop an analytical method for simultaneous equation method for estimation of Aspirin and Omeprazole by using UV Spectroscopy. The developed method was validated for linearity, Accuracy, precision, ruggedness and results were within the limits according to $\mathrm{ICH}$ guidelines. The proposed method was cost effective, simple, rapid, economic, cheap, precise and robust. The above method can be used for routine analysis of Aspirin and Omeprazole in bulk and Tablet Dosage Form 


\section{ACKNOWLEDGEMENT}

The author's were thankful to Principle of TVES's HLMC College of Pharmacy, Faizpur (MS) INDIA for providing necessary help for work.

\section{REFERENCES}

1. Yosprala prescribing information. Princeton, NJ: Aralez pharmaceuticals US Inc. 2016.

2. FDA Approves Yosprala (aspirin and omeprazole) for secondary prevention of cardiovascular and cerebrovascular Disease in patients at risk for aspirin associated gastric ulcers. 2016.

3. Patta S, Afreen S, Tappa S, Nagarajan G, GnanaPrakash K. Simultaneous estimation of aspirin and omeprazole (Yosprala) in bulk by UV-spectroscopy. J Drug Deliv Ther. 2017;7:87-91.

4. SureshKumar S, Jamadar LD, Bhat K, Musmade PB, Vasantharaju SG, Udupa N. Analytical method development and validation for Aspirin. Int J Chem Tech Res. 2010; 2:389-399.
5. Kalakonda SN, Mohammad BD, Kalyani P, Dussa KK. Development and validation of RP-HPLC method for the estimation of Omeprazole in bulk and capsule dosage forms. Int Curr Pharm J. 2012;1:195-205.

6. Sadhana R, Fanse S. RPHPLC method for Simultaneous Estimation of Lansoprazole and aspirin in Bulk and Laboratory Mixture. J Adv Pharm Edu Res. 2015; 5:87.

7. Kalshetti MS, Supriya K, Neha C, Swami D, Bharti K. Development and validation of RP-HPLC method for simultaneous estimation of aspirin and omeprazole in dosage. Int J Res Pharm Sci. 2017;2:45-51.

8. Hajera NK, Swapna SB, Mohammad Z, Vishvanath BB. Development and Validation of RP-HPLC Method for Simultaneous Determination of Aspirin and Omeprazole. Der Pharma Chemica. 2017;9:55-58.

9. Ghulam M, Shujaat AK, Arham S, Arshad M, Muhammad BA, Kalsoom F, et al. Development of a UV-spectrophotometric method for the simultaneous determination of aspirin and paracetamol in tablets. Sci Res Essays. 2001;6:417-421. 